bathed in sweat on a stretcher in a corner. "Typhoid," a nurse assured me. "We already referred three cases." Apparently there are no possibilities of verifying the diagnosis, nor of sorting out the source; it was just a matter of waiting with resignation until the next patient arrived. It did not surprise me that there was typhoid on the island. Latrines are very few, the soil is rock hard, and drinking water is rationed. On the little square in front of the mission, people queued at the well in the middle of the night to fill their buckets. Typhoid is not the only epidemic that threatens the island. What will happen if cholera gets a foothold? This is likely to happen because cholera has spread rapidly all over Latin America, though so far it has spared Haiti.

\section{Missions and churches}

The health facilities on the island are insufficient for 80000 inhabitants. The one and only hospital-40 beds, and run by American missionaries-holds its own with a hospital in rural Africa. The sisters try to make ends meet. "The $x$ ray is out of order and the laboratory deteriorates," the doctor told me, sighing. "We did have a good laboratory technician but he left for the States. He broke a new person in, and this one is training in his turn an assistant." She made a gentle undulating downward movement with both hands. "I cannot do everything myself, can I? I would like to train more nurses and organise an outreach programme - the people on the other side of the island never see a doctor."

The cooperation between the different denominations is formal and seems a bit cool. "You know," the priest tells me, "the Protestants are so strict. Before the outpatient department starts the people are supposed to pray; only then do they receive a serial number. One prays in the church and not in the hospital, what do you think? But to be honest, I believe we see it more as a problem than do the
Haitians. They do not so much mind praying, and it is the same to them to which god. If they do not have time, they send their cousin to pray and collect the number." Another missionary told me, however, that it is unbelievable how someone who lives in sin (the priest is a heavy smoker) can guide the people along the correct path.

\section{A medical mission}

Back in Port au Prince everybody wanted to get hold of the hot news of the situation on the island. It is remarkable that so few people from Port au Prince have visited the island themselves-the island is easily visible from the harbour. The situation is not too complicated: one doctor for 80000 inhabitants is very little, and there is a great lack of drugs and supplies.

Médecins Sans Frontières could well support the island with both staff and supplies and set up outreach activities. Before it is too late, action is needed to deal with the typhoid epidemic and a contingency plan in case of a cholera epidemic has to be prepared. Training of the local health workers will be an important component in combating these two diseases. Malaria and tuberculosis are both killer diseases on the islandit will be necessary to train microscopists to diagnose both diseases correctly.

The other organisations are glad that a Médecins Sans Frontières team will be arriving. The extra input for the island is appreciated. However, there is little cooperation with the government, which came to power with a coup and therefore is not recognised by most political parties in Haiti. Haiti gets international attention because of the number of Haitians who try to reach the United States by boat in search of a better future. This will make it easier to find funding for a programme, especially as many refugees come from Ile de la Gonave.

(Accepted 21 May 1993)

\title{
Medical practice guidelines: lessons from the United States
}

\author{
Andrew Farmer
}

Clinical guidelines, or protocols, have been devised by many different groups, often with differing aims. Some aim to reduce variations in care by using guidelines, while others seek to improve outcomes. Guidelines have long been used in the United States to try to control the behaviour of the medical profession-and the cost of health care. The "effectiveness initiative," run by the Agency for Health Care Policy and Research spawned much activity among other groups, including the American Medical Association and the American College of Physicians. The experience of the Americans in analysing data to gauge effectiveness and then in disseminating good practice may help British moves in this direction. In particular, it is often hard to get guidelines adopted in practice; doctors have to be exposed to the same message in different forms.

Health Services Research Unit, Department of Public Health and Primary Care, University of Oxford, Radcliffe Infirmary, Oxford OX2 6HE

Andrew Farmer, general practice research fellow

BMF 1993;307:313-7 a recommendation for patient management that identifies one or more strategies for treatment. Traditionally practice guidelines are viewed as a mechanism for offering advice to doctors about their clinical management. Guidelines were originally intended for junior doctors or physician assistants, but the idea has been developed by different groups. The ultimate aim, of course, is to inform doctors of "the right thing to do." However, the "right thing" ultimately depends on judgments based on personal values. Different groups have different agendas. Some want to control costs. Others want to reduce the variations between doctors in an attempt to manage care. Others want to improve the outcomes of medical care by basing it more firmly on the results of research data. The user-whether doctor, patient, or manager-needs to understand something about the objectives of the guideline, and the method of developing it, to judge whether the final balance of opinions is fair and reasonable.

This report looks at the development of practice guidelines in the United States and draws parallels with the current situation in Britain. Where do guidelines fit in with the current interest in research about the outcomes of medical care? How are practice guidelines being used? What are their strengths and weaknesses, 


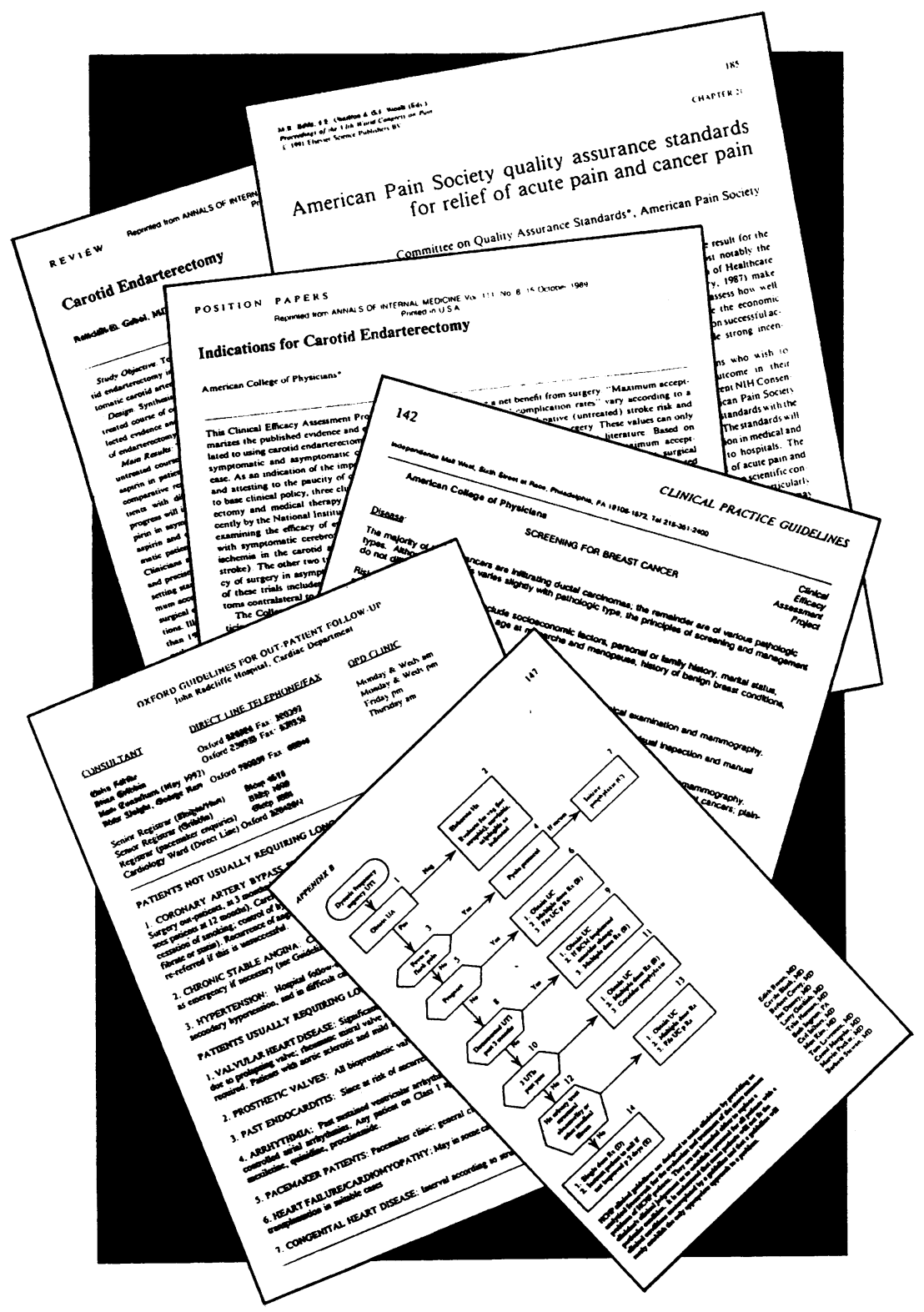

and how might they be used more effectively in the United Kingdom?

\section{Background}

Policy makers in the United States see practice guidelines as a possible way of controlling the behaviour of the medical profession. ${ }^{2}$ They are an attempt to control the growth in health care spending which began in the mid-1960s, with the introduction of the right to free, almost unlimited health care for the poor and elderly under the Medicaid and Medicare programmes. Health maintenance organisations and professional standards review organisations were attempts to establish local control over costs. When they failed to bring costs under control alternative solutions were proposed.

More centralised mechanisms for control were introduced in the early $1980 \mathrm{~s}$. The prospective payment system for Medicare offers hospitals a fixed payment for treating patients with a particular diagnosis. The professional standards review organisations which were basically state or local medical societies, were replaced by peer review organisations. These have a state wide remit and are funded on the basis of competitive contracts. Their role is to ensure that money spent on health care through Medicare is used in accordance with recognised standards of care. Difficulties with developing standards of care encouraged interest in outcome research.
The "effectiveness initiative" was established by William Roper, then head of the Health Care Financing Administration in Washington, the body responsible for administering Medicare. He brought together doctors engaged in health service research and data analysis for a series of seminars in 1987. Out of those seminars came an initiative to improve the quality of health care. Among the participants were three influential doctors. Robert Brook, a researcher from the Rand Corporation, a think tank in California, had developed criteria for judging whether medical procedures were carried out appropriately. ${ }^{3}$ David Eddy, a medically qualified mathematician, had publicised the idea of projecting results from research studies to populations in which the data for firm conclusions were lacking. ${ }^{14}$ John Wennberg, a health service researcher, had shown the considerable variation in rates of common medical procedures between small areas. ${ }^{5} \mathrm{He}$ made a case for this variation being due to differences in the way doctors practise medicine rather than to genuine differences in demand from different types of people.

Before 1989 most of the federal effort in technology assessment was based within the National Center for Health Services Research. Roper launched the effectiveness initiative in 1988, claiming a role for the Health Care Financing Administration in outcomes research. ${ }^{6}$ This provoked a debate, with several groups, including the National Institutes for Health, the National Center for Health Services Research, and the Health Care Financing Administration, each claiming a role in the programme. Eventually a bill was introduced into Congress that adopted the name Agency for Health Care Policy and Research, and it became the basis for legislation. ${ }^{7}$ The Agency for Health Care Policy and Research developed from the National Center for Health Services Research, also taking on work formerly directed by the Health Care Financing Administration. The legislation setting up the agency made explicit the role of the government in developing practice guidelines.

The new agency was also noted by industry, hospital providers, and academic bodies, partly because of its high political profile and partly because of the large amount of new funding available. Other resources were diverted into similar areas of research, with a rapid growth in the guidelines industry. Books were published about the development and design of guidelines $^{89}$ and many journal articles written..$^{10}$ The American Medical Association appointed a director of quality assurance and encouraged the development of guidelines within specialty groups. The guideline development programme of the American College of Physicians, in existence since $1982,{ }^{12}$ was much admired. Nevertheless, there was uncertainty about how guidelines were supposed to change medical practice.

Those who paid for health care, including government and insurance companies, considered making practice guidelines more widely available. They were interested to see whether this would be a better method of regulating doctors than looking back through medical notes to see if standards had been met.

In the United Kingdom the Department of Health has commissioned evidence based analyses of health care problems, but with no emphasis on mathematical manipulation of data or consensus statements (for example a report into the management of stroke $\left.{ }^{13}\right)$. The staff responsible for NHS research and development strategy $^{14}$ have published a report which sets an agenda for assessing treatments and implementing those practices known to be effective. ${ }^{15}$ The Cochrane Centre has been set up to collate the results of randomised trials. ${ }^{16}$ However, decisions about which treatment to use may not easily be projected to groups 
not tested within a trial. A report for the Agency for Health Care Policy and Research called for the analysis of clinical trials in the light of observational studies. ${ }^{17}$ Guidelines have a place in this process, but there are lessons to be learnt from the United States in making the best use of time and resources. The following examples illustrate the different ways in which guidelines are being used.

\section{Guidelines for risk management}

In the states of Massachusetts and Maine practice guidelines have been drawn up to reduce the risk of litigation. In Massachusetts the cost of malpractice insurance fell after guidelines were introduced for administering an anaesthetic. ${ }^{18} \mathrm{~A}$ similar initiative has now been introduced in Maine, where the legislature has incorporated four sets of practice guidelines into state law. It has altered the judicial process so that a doctor accused of malpractice may ask for a judicial review, establish the precise grounds of the charge of malpractice, and, if appropriate, show adherence to a guideline as sufficient evidence of competent practice.

These particular guidelines were developed from advice given by the Medical Mutual Insurance Company of Maine. The company had drawn up minimum standards and suggested that sticking to them would reduce the risk of being sued. The guidelines set out minimum standards for care-for instance,

- anaesthesia machines capable of delivering less than $18 \%$ oxygen shall not be used

- immediately before the start of an anaesthetic procedure check equipment, drugs, and gas supply

- take a chest $x$ ray film before anaesthesia in defined groups of patients. ${ }^{19}$

One aspect of the guideline concerned standards for anaesthetic machines. When it became obvious that there were too few machines conforming to the standard available in the state the guideline was altered to permit the lower specification. Downward pressure on standards from financial constraints can easily be concealed within the process of writing guidelines.

The public must be protected from incompetent doctors by ensuring that medical practice reaches a minimum standard. In the United Kingdom the public are protected through, for example, the courts, service committee hearings, and the General Medical Council. A hearing by any of these bodies would, in part, consist of developing a standard by which the conduct of the doctor could be judged. Any extension of formal standards requiring proof of compliance would present the majority of competent doctors with additional work in producing more comprehensive notes or completing checklists. Minimum standards also require a complicated process of amendment to change them. Demonstrating adherence to minimum standards may be unavoidable where patients could come to harm. Nevertheless, the money or energy spent in the process may not produce an overall improvement in services.

\section{Guidelines for quality systems}

The idea of designing a system of care to produce a continuing improvement has been borrowed from industry. Quality improvement is a philosophy in which management structures are brought closer to the manufacturing process, emphasis is placed on the consumer, systems planned carefully, and key steps identified to improve performance. ${ }^{20}$

The Harvard Community Health Plan was one of the first health maintenance organisations to develop the use of guidelines expressed as algorithms. The guidelines were designed as flow diagrams, to show the key steps in the process of diagnosis, use of tests, and referral. ${ }^{21}$ The health plan introduced its programme for guideline development in 1985 . The original intention was to ensure that the organisation had a uniform response to common problems-for instance, the management of a patient with abnormal cervical cytology. ${ }^{21}$ Under the leadership of Donald Berwick, however, the guidelines became incorporated into the philosophy of quality management in health care. ${ }^{20}$

The guidelines are used to identify steps that can be carried out in a different way, delegated, or made more consistent. For instance they have been used to ensure that patients are routinely recalled for certain procedures and to check that the timing of groups of investigations is coordinated. The guidelines are constantly amended by everyone involved in the process of care. The guidelines change as new insights emerge into ways of improving the quality of health care.

The coordinated development of health care interventions has also been developed in the United Kingdom. The National Breast Screening Programme used performance indicators, such as the proportion of patients screening positive at each site, the proportion of breast cancers positively identified, and the compliance rates. Each part of the screening programme was set up with a training package. For instance, general practitioners and their staff were given detailed instructions about the steps they would need to take to ensure that all eligible women were called for mammography. The programme illustrates how a clear plan or guideline for care, planned across disciplines, can be used as the basis for a national programme. The barriers to similar programmes being implemented at a local level often include the lack of time among key people to plan and entrenched attitudes among those with influence. A national programme with central funding was able to overcome some of these barriers; local initiatives need to look for opportunities and sympathetic collaborators to achieve the same result.

\section{Guidelines for regulation}

Guidelines can be used for regulation either by offering an incentive if the work is carried out according to the guideline or a penalty if the regime is not followed. The monitoring of guidelines inevitably relies on recording a series of actions. The regulations relating to health checks under the new contract in 1990 specified a series of things to be done..$^{22}$ Such guidelines are useful if they are widely agreed to be sensible, but if they suggest ineffective procedures such as routine urine tests they become discredited. ${ }^{23}$ An alternative approach to regulating medical practice is to set outcome targets and monitor the results. At the level of an individual practitioner or practice, however, this will work only if the number of outcomes is sufficiently large to outweigh differences in rates caused by chance. How is it possible to use guidelines in regulation?

Doctors practising in Louisville, Kentucky, have found themselves facing intense competition over fees and services. Like many doctors across America they have formed an independent organisation to bargain with insurance companies for providing services. However, as part of their strategy they have undertaken to carry out internal quality review work within the organisation and to select doctors on the basis of their ability to provide a high standard of care at a reasonable cost. Guidelines are one way in which the quality of the care is planned and encouraged.

The doctors in Louisville have commissioned guidelines through an executive group but draw on a wide group of doctors to make the decisions. The panel of doctors use nationally developed guidelines and 
published reviews to draw up algorithms or lists of criteria for care. These guidelines are then accepted by the insurance company. The guidelines are used as the basis for quality assurance by both the doctors and the insurance company. The guidelines sometimes present an opportunity to adjust the payments system. Instead of receiving a routine payment for an annual chest $x$ ray examination for instance, a doctor would be paid for offering routine advice about dietary measures.

The use of guidelines in the United Kingdom to specify services is just starting. Payments for diabetic and asthma care in general practice will involve local negotiations with family health service authorities about the precise criteria to be applied. Practices should not be expected to show blanket adherence to a complicated set of guidelines drawn up to describe good practice. The selective application of a few specific criteria, based on the guidelines and agreed with the profession locally, will ensure that the guidelines are taken seriously and used as a basis for planning local services and educational interventions.

\section{Guidelines for education}

The American College of Physicians has a well developed programme for guideline development. ${ }^{12}$ Once a subject is identified an academic group is asked to provide a succinct but thorough review of the literature, including some simple projections about costs and benefits. They are asked to provide a draft guideline based on a standard model. The literature review is then peer reviewed, as for any published paper. The guideline is passed to a representative group, modified, passed back to the authors, modified, and then eventually approved by an executive group within the college. The paper is written in a way that helps doctors relate it to their own routine practice.

A single shot is unlikely to get the message across. Doctors have to be exposed to the same message in several different forms such as lectures, discussions with colleagues, feedback on performance, and written prompts. In Canada, where the rate of caesarean deliveries is as high as in the United States, attempts have been made to identify influential doctors (opinion leaders) among obstetricians and provide them with the opportunity to talk to their colleagues and lead seminars. ${ }^{24}$ The drug industry in the United Kingdom has already learnt the message and may identify consultants sympathetic to their products and offer them a platform.

Purchasing authorities such as district health authorities, and bodies with wider responsibility such as the regional health authorities, could learn from these approaches to influencing care. They include distilling the message down to a few key phrases, using attractive presentation material, and using local clinicians respected by their colleagues to get the message across. ${ }^{25}$ Similar techniques have been used in the United States in programmes to reduce the use of sedatives in nursing homes, with some success. ${ }^{26}$

There are currently many attempts to develop and disseminate guidelines in the United Kingdom. In High Wycombe junior staff are receiving guidelines as A5 laminated sheets in a pocket folder (C Foote, personal communication, 1993). The Northampton specialty liaison group project has commissioned over 30 sets of guidelines, each written by small groups of general practitioners and specialists (A Willis, personal communication, 1993). Other efforts to develop referral guidelines have been extensively reviewed, ${ }^{27}$ but formal evaluations of their impact are still limited. Groups are attempting to set up a central clearing house for guidelines to prevent duplication of effort and ensure they are evaluated. ${ }^{28}$

Technology assessments form part of the NHS research and development strategy ${ }^{15}$ and provide a review of the literature on which practice can be based. Technology assessment provides the basic material from which guidelines can be developed. A recent report on the management of glue ear has provoked discussion about the need to issue guidelines to change practice. ${ }^{29}$ Systems to permit computer aided decision support are now available for several general practice computing systems. ${ }^{30}$ These systems have not been formally evaluated but offer one possible solution to implementing guidelines.

At present the peer review of consensus statements and guidelines depends on the policy of the journal in which they are published. Recent publications include statements on carotid endarterectomy ${ }^{31}$ and depression..$^{32}$ There is a profusion, however, of bits of paper containing sensible, but tedious advice. Perhaps one function of a central clearing house for guidelines would be to advise those producing these documents on presentation, to consider who might appropriately receive them first, to ask whether the service implications have been considered and whether training packages have been developed, and to encourage the use of attractive summaries to get over the key points.

\section{Conclusions}

Guidelines are here to stay and will continue to be developed and used for educating and regulating the practice of doctors. The use of formal techniques of meta-analysis offer the prospect of making better decisions about the use of resources. Guidelines offer groups within the medical profession a mechanism for agreeing on standards. If different groups come up with different standards, there is a possibility of comparing the alternative management strategies. At present the minute variations in patterns of care make it difficult to evaluate one strategy against another.

Despite their knowledge, skills, and experience doctors are not necessarily the best managers of other people or even of their own time. If doctors can distil some of their experience into the form of guidelines it will help managers improve services. Guidelines may provide the template on which services can be designed and coordinated.

Finally, one of the characteristics that has marked the development of clinical standards is the involvement of academics and senior members of the profession. These individuals are sometimes insulated from the day to day pressures involved in providing medical care. They may have junior staff to provide care, or their part time contract may offer a respite from a stressful environment. Under these circumstances the guideline they produce may be less concerned with the improvement of day to day standards and more concerned with attempts to produce academic credibility or argue for resources. Sometimes it may be too painful for a senior doctor to admit to practices that are less than ideal. Unless a guideline accurately reflects the routine working practices of most doctors it will act only as a gold standard to be admired. Rather, it should be an explanation of unsatisfactory practices, a plea for better coordination, and a blueprint for simple measures to improve the state of affairs. Perhaps doctors need to be less idealistic and more honest about their present working conditions in order to describe the guidelines to which their practice conforms.

This work on which this paper is based was carried out as a Harkness fellow of the Commonwealth Fund of New York. I thank David Matchar and Robert Sprinkle of the Center for Health Policy Research and Education at Duke University, North Carolina, for their support and advice. I also thank Angela Coulter and Ruairidh Milne for their comments. 
1 Eddy DM. Assessing health care practices and designing practice policies. Philadelphia: American College of Physicians, 1992.

2 Gray BH. The legislative battle over health services research. Health Affairs 1992;11:38-66.

3 Fink A, Kosecoff J, Chassin MR, Brook RH. Consensus methods: characteristics and guidelines for use. Am $\mathcal{F}$ Public Health 1984;74:979-83.

4 Eddy DM. Anatomy of a decision. FAMA 1990;263:441-3.

5 Wennberg JE, Freeman JL, Culp WJ. Are hospital services rationed in New Haven or over utilized in Boston? Lancet 1987;i:1 185-9.

6 Roper WL, Winkenwerder W, Hackbarth GM, Krakauer H. Effectiveness in health care: an initiative to evaluate and improve medical practice. $N$ Engl $f$ Med 1988;319:1197-1202.

7 Brown LD. Political evolution of federal health care regulation. Health Affairs 992;11:17-37.

8 Woolf SM. AHCPR Interim Manual for Guideline Development. Washington, DC: Agency for Health Care Policy and Research, 1991.

9 Field MJ, Lohr KN, eds. Clinical practice guidelines: directions for a new program. Washington, DC: National Academy Press, 1990.

10 Eddy DM. Practice policies-guidelines for methods. FAMA 1990;263: 1839-41.

11 Audet A, Greenfield S, Field M. Medical practice guidelines: current activities and future directions. Ann Intern Med 1990;113:709-14.

12 Schwart JS, Ball JR. Safety, efficacy, and effectiveness of clinical practices: a new initiative. Ann Intern Med 1982;96:246-7.

13 Wade D. Epidemiologically based needs assessment: stroke. London: NHS Management Executive, 1992.

14 Research for health: a research and development strategy for the NHS. London: HMSO, 1991.

15 Department of Health. Assessing the effects of health technologies. London: HMSO, 1992

16 Cochrane's legacy. Lancet 1992;340:1131-2.

17 Agency for Health Care Policy and Research. The Feasibility of Linking Research-Related Data Bases to Federal and Non-Federal Administrative Data Bases. Washington, DC: US Department of Health and Human Services, 1991.
18 McGinn P. Practice standards leading to premium reductions. Am Med Nerws 1988;Dec 2:1.

19 State of Maine. Maine medical liability demonstration project. Sec 424 MRSA c21, sub-c IX 1991

20 Berwick DM, Enthoven A, Bunker JP. Quality management in the NHS: the doctor's role-1. BMf 1992;304:235-9.

21 Schoenbaum SC, Gottleib LK. Algorithm based improvement of clinical quality. BMF 1990;301:1374-6.

22 Department of Health. General practice in the National Health Service: the 1990 contract. London: Department of Health, 1989.

23 Mant D, Fowler G. Mass screening: theory and ethics. BMF 1990;300:916-8.

24 Lomas J, Enkin MW, Anderson GM, Hannah WJ, Vayda E, Singer J. Opinion leaders vs audit and feedback to implement practice guidelines: delivery after previous caesarian section. $¥ A M A 1991 ; 265: 2202-7$.

25 Soumerai SB, Avorn J. Principles of educational outreach ('academic detailing') to improve clinical decision making. $¥ A M A$ 1990;263:549-56.

26 Avorn J, Soumerai SB, Everitt DE, Ross-Degnan D, Beers MH, Sherman D, et al. A randomized trial of a program to reduce the use of psychoactive drugs in nursing homes. $N$ Engl f Med 1992;327:168-73.

27 Russell IT, Grimshaw J. The effectiveness of referral guidelines: a review of the methods and findings of published evaluations. In: Coulter A, Rowland M, eds. Hospital referrals. Oxford: Oxford University Press, 1992:179-211.

28 Littlejohns P, Collier J, Hilton S. Guidance on guidelines. BMF 1992;305: 1098.

29 Glue ear guidelines: time to act on the evidence, Lancet 1992;340:1324-5.

30 Purves I, Cowley C, Bainbridge M, Grimshaw J. Using guidelines. BMF 1992;305:1364.

31 Brown MM, Humphrey PRD. Carotid endarterectomy: recommendations for management of transient ischaemic attack and ischaemic stroke. $B M F$
1992;305:1071-4.

32 Paykel ES, Priest RG. Recognition and management of depression in general practice: Consensus statement. BMF 1992;305:1198-1202.

(Accepted 11 May 1993)

\section{OBITUARY}

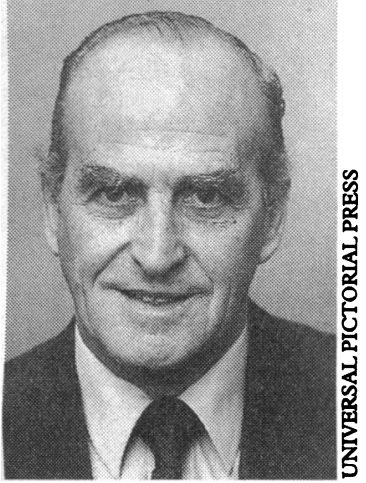

Lord Winstanley
Obituaries must be submitted exclusively to the BMF; they should be under 250 words and submitted within three months of the person's death. We welcome self written obituaries and good quality, recent photographs, and, as a medical journal, we encourage authors to include the cause of death.

\section{Lord WINSTANLEY}

MRCS, LRCP

Michael Winstanley enhanced the medical profession's standing in the eyes of the public in so many ways. He was a concerned and dedicated general practitioner possessed of considerable powers of advocacy and persuasion, which he exercised with a unique version of a public bedside manner. This highly personal style, admirably suited to the presentation of diagnostic and reasoned argument, he employed - with various subtle adaptations according to different atmospheres-to great effect in the House of Lords, in the House of Commons, for his many radio and television performances on public platforms, and in after dinner speeches.

Many sound judges regarded him, in his prime, as one of the best, if not the best, after dinner speaker in Britain. He was always witty and was effective, for he had the skill to put people at their ease before trying to get any message across: he possessed an uncanny sensitivity to the nature of his audience. Much of this was because he was an astute observer of human nature and a good listener.

Although his interests were wide, there is no doubt in my mind that it was when he spoke on the problems of patients, doctors, nurses, and the health servce that he had the ear of the Commons and the Lords. He had the knack of the natural advocate of illustrating his most telling points with anecdotes from his own experience. A doctor's son, he was steeped in the medical politics of Lancashire and Cheshire during the formative years of the NHS, and by the late 1950 s he was often writing and broadcasting on the problems of health care. This interest coupled with his commitment to the Liberal party made him a much sought after candidate for parliamentary seats. He was a spectacular vote winner for the Liberals, and in the general election in March 1966 he gained an unexpected triumph for his party when he overturned a Conservative majority of 8691 at Cheadle.

He greatly influenced and assisted David Steel in piloting through parliament the Abortion Act of 1969. He then expanded his health brief by relating the diverse medical problems of our age to the contamina- tion and destruction of the environment, the stress and anxiety of modern work conditions, and the ever increasing but unsatisfied demand for reasonable homes for all. This led to increasing involvement in moves to protect the countryside; he had a particular love of the lake district. It was therefore no surprise when he was appointed chairman of the Countryside Commisison in 1978-nor, indeed, when he was sacked from the job by Margaret Thatcher in 1980, for there was no more articulate and effective critic of what he regarded as some of the false values of Thatcherism than Winstanley.

He had great enthusiasm for sport, having been a fine cricketer (opening bat), rugby player (centre three quarter), golfer, tennis player, and snooker player. As one of his contemporaries from his student days told me: "Michael could have been a superb and probably international performer in any one of the sports in which he participated, but he was typical of the talented English amateur-he played a large number well simply for the enjoyment."

Winstanley was a life enhancer.-HoosoN

MEREDITH MACARDLE writes: Lord Winstanley was the first chairman of the All-Party Parliamentary Voluntary Euthanasia Group, which he helped set up in 1991. He had a deep commitment to patients' rights as well as to doctors' needs for legal protection in a changing world. Thus he was keen to see the Medical Treatment (Advance Directives) Bill set before parliament; it was introduced in March by Lord Allen of Abbeydale.

Michael Platt Winstanley, a life peer since 1975 and a former general practitioner, died 18 fuly. Born Nantwich, 27 August 1918; educated Manchester Grammar School, Manchester Univesity (MRCS, LRCP 1944). General practitioner in Urmston, Manchester, 1948-66. Member of Lancashire Local Medical Committee 1954-66 and Lancashire Executive Council 1956-65; spokesman for Manchester division of BMA 1957-65. Member of parliament (Liberal) for Cheadle 1966-70 and for Hazel Grove for several months in 1974. President and chairman of several national organisations, including the Countryside Commission 1978-80; broadcaster on television and radio. Survived by second wife, foyce, and two sons and a daughter. 